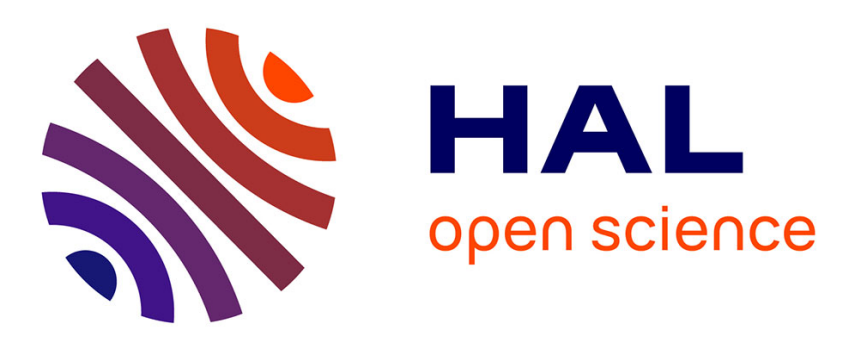

\title{
Touching and interacting with inaccessible cultural heritage
}

Théophane Nicolas, Ronan Gaugne, Cédric Tavernier, Quentin Petit, Valérie Gouranton, Bruno Arnaldi

\section{- To cite this version:}

Théophane Nicolas, Ronan Gaugne, Cédric Tavernier, Quentin Petit, Valérie Gouranton, et al.. Touching and interacting with inaccessible cultural heritage. Presence: Teleoperators and Virtual Environments, 2015, 24 (3), pp.265-277. 10.1162/pres_a_00233 . hal-01218223

\section{HAL Id: hal-01218223 \\ https://inria.hal.science/hal-01218223}

Submitted on 20 Oct 2015

HAL is a multi-disciplinary open access archive for the deposit and dissemination of scientific research documents, whether they are published or not. The documents may come from teaching and research institutions in France or abroad, or from public or private research centers.
L'archive ouverte pluridisciplinaire HAL, est destinée au dépôt et à la diffusion de documents scientifiques de niveau recherche, publiés ou non, émanant des établissements d'enseignement et de recherche français ou étrangers, des laboratoires publics ou privés. 


\title{
Touching and interacting with inaccessible cultural
}

\section{heritage}

Théophane Nicolas ${ }^{1}$, Ronan Gaugne ${ }^{2}$, Cédric Tavernier ${ }^{3}$, Quentin Petit ${ }^{4}$, Valérie Gouranton $^{5}$, Bruno Arnaldi ${ }^{5}$

\author{
${ }^{1}$ Inrap, France \\ ${ }^{2}$ Université de Rennes 1/IRISA/Inria, France \\ ${ }^{3}$ Image ET, France \\ ${ }^{4}$ CNRS/IRISA/Inria, France \\ ${ }^{5}$ Insa de Rennes/IRISA/Inria, France
}

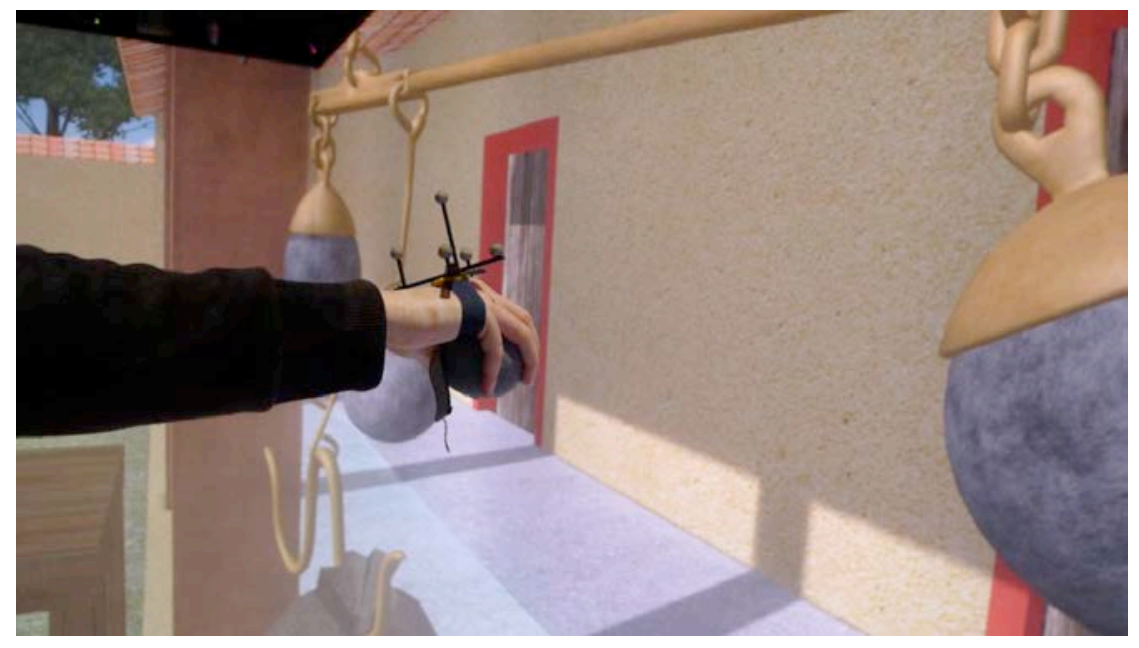

Abstract. Sense of touch provides a particular access to our environment, enabling a tangible relation with it. In the particular case of cultural heritage, 
touching the past, apart from being a universal dream, can provide essential information to analyze, understand, or restore artifacts. However, archaeological objects cannot always offer a tangible access, either because they have been destroyed or too damaged, or because they are part of a larger assembly. In other cases, it is the context of use that has become inaccessible, as it is related to an extinct activity. We propose a workflow based on a combination of computed tomography, 3D images, and 3D printing to provide concrete access to cultural heritage, and we illustrate this workflow in different contexts of inaccessibility. These technologies are already used in cultural heritage, but seldom combined, and mostly for exceptional artifacts. We propose to combine these technologies in case studies corresponding to relevant archaeological situations.

Keywords: Computational archaeology, CT scan, Digitization, mixed reality, 3D printing, virtual heritage

\section{Introduction}

In cultural heritage, archaeologists often face the need to study, document, and promote artifacts when they are not accessible, or when their use is no longer accessible. For example, artifacts may be encased in corroded materials or in an ash block, or integrated with, and inseparable from, larger assemblies (e.g., manufactured objects with several components). In this case, only a destructive analysis can provide access to the concealed artifact to enable its study. In other 
cases, artifacts may have vanished, because the constituting material was disaggregated (typically, organic matter in a cremation block), but a footprint remains, the destructive exploration of which would be fatal. We can also quote the case of artifacts that are difficult to physically study or exhibit because of their size. A tiny object could not be handled or presented to public because it is not to human scale. When artifacts have been preserved, it is their context of use which is no more accessible because this is related to an activity that no longer exists, or requires additional objects to operate.

We aim to propose a workflow for providing concrete access to inaccessible archaeological artifacts or to their use, by combining advanced digitizing techniques, such as computerized tomography (CT) (Herman, 2009) or photogrammetry, with 3D printing and virtual reality. We will illustrate this workflow with three different contexts of inaccessibility corresponding to common and realistic situations faced by archaeologists: vanished material, tiny material, and human activity based on a destroyed assembly. For each context, we propose a tangible object to help cultural heritage professionals in studying, restoring, or valorizing the artifacts. 
Three-dimensional technologies are increasingly used in archaeology and cultural heritage, mainly to create digital images that can be studied, modified, stored, and exhibited. Data acquisition from digitization of heritage artifacts is performed through various technologies, such as laser scan (Balleri et al., 2014; Lapp et al., 2014), photogrammetry (Nicolae et al., 2014; Gallo et al., 2013) or CT scan (Uda et al., 2005; Hugues, 2011; Harvig et al., 2012). The works of Re et al. (2015) and Stelzner et al. (2010) illustrate particularly the interest in CT scan to guide analysis, extraction, and restoration of encased and damaged artifacts. New uses for this 3D data have been found by interactive capacities enabled by augmented reality (MagnenatThalmann \& Papagiannakis, 2005; Haugstvedt \& Krogstie, 2012; Liestøl, 2014), virtual reality (Morgan, 2009; Bale et al., 2011), and more recently $3 \mathrm{D}$ printing. The use of $3 \mathrm{D}$ printing technologies for cultural heritage is currently growing (Scopigno et al., 2014), as illustrated in (Arbace et al., 2013), for restoration purposes, and in (Barreau et al., 2014) for exhibition purposes. The projects presented in (Laycock et al., 2012), (Hassmann et al., 2012) and (McKnight et al., 2015) both propose the use of 3D printers, combined with CT images, to reproduce high-value pieces, Chinese chess pieces in the first case, 
gold jewels in the second case, and bones assembly from an animal mummy in the third case. These 3D printed surrogates can then be used both for detailed study and in contexts such as education, communicating with the public, or substituting the inaccessible original in open exhibitions or for physical handling by school children. These works demonstrate the added value of combining medical images and 3D. Nevertheless, in current practice, the joint use of CT acquisition, 3D visualization, and 3D printing has been limited to exceptional artifacts, due to the difficulty of accessing and combining the different technologies. In contrast, we believe that it can emerge as an approach routinely used by cultural heritage professionals, provided the new data sources are fully integrated into the professional workflows (Arnold, 2014). In a preliminary study (Nicolas et al., 2014), we have demonstrated the efficiency and usefulness of a workflow combining medical images, 3D images, and 3D printers, aiming at proposing a new nondestructive scientific study process. We now illustrate how the touchable objects produced with this workflow can be integrated in the daily work of archaeologists. Such workflow can be applied to various common situations, and these combined technologies should constitute a usual toolbox in this domain. 
2. Archaeological Context of the Work

We now detail the archaeological context of the three case studies: the disaggregated bones of a Middle Bronze Age cremation burial, a small Gallo-Roman bronze sculpture of a centaur, and a Gallic weighing activity, based on fragments of weighing elements.

\section{The funerary urn of Saint-Pair-sur-Mer:}

The development project of Ardilliers BIA $^{1}$ is the origin of the archaeological excavation conducted by H. Lepaumier $\left(\operatorname{Inrap}^{2}\right)$ in the municipality of Saint-Pair-sur-Mer (Manche, France). The excavation revealed a circular funerary enclosure and four funerary deposits dating to the Middle Bronze Age (Figure 1). A significant bone mass representing three individuals was identified in the only cinerary deposit in a ceramic urn; the bones are, however, highly deteriorated.

\footnotetext{
${ }^{1}$ Business Improvement Area

${ }^{2}$ French National Resesearch Institute of Preventive Archaeology
} 


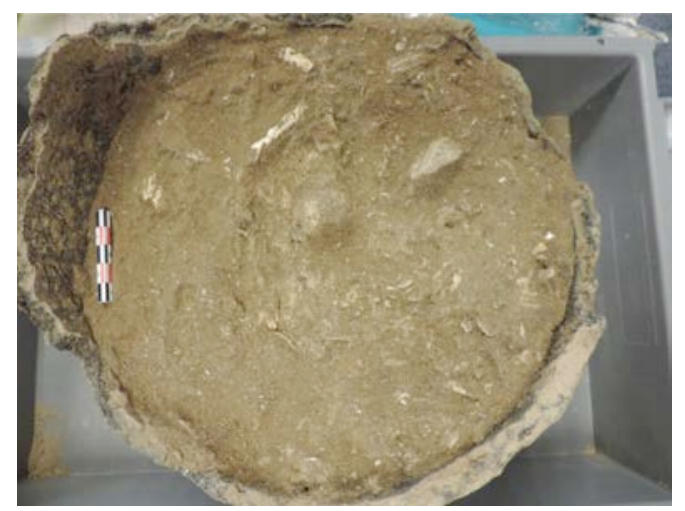

Figure 1. The funerary urn of St-Pair-sur-Mer. CM. Le Puil-Texier, Inrap

\section{The Centaur of Chateaugiron:}

The development project of La Perdriotais BIA is the origin of the archaeological excavation led by I. Catteddu (Inrap) in the municipality of Chateaugiron (Ille-et-Vilaine, France). Identified occupations belong to Gallic, Gallo-Roman, medieval, and modern periods. A bronze centaur (Figure 2), of a size of $5.5 \mathrm{~cm}$ high, $5 \mathrm{~cm}$ long, and $1.5 \mathrm{~cm}$ deep and dating to the beginning of our era, was unearthed. The discovery of this bronze statuette associated with Roman coins and diverse dishes allows us to consider the presence of a major occupation. 


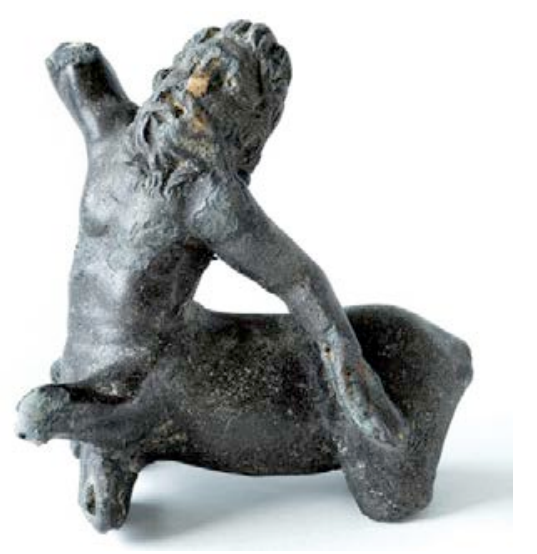

Figure 2. The bronze centaur. CD. Gliksman, Inrap

\section{The Iron Age weighing scales:}

The excavation of the site la Claraiserie, in Ossé (Brittany, France), conducted by J. Gall (Inrap), revealed part of an Iron Age farm and field system. The site was occupied from the second century BCE onwards and abandoned during the first century AD, like many other farms of this type. A large number of objects were found, including a large range of agricultural tools, and elements of hunting weapons. Horse bits and fragments of a steelyard balance, probably for the weighing of farm produce, were also discovered. This single beam balance, with an unequal arm, is similar to a bronze steelyard balance unearthed in the excavation of the ancient occupation of Parville 
(Dagmar Lukas, Inrap) (Eure, France) in 2006. The fragments from the Ossé excavation also included several spherical weights made out of granite. The weight studied here has a diameter of $8 \mathrm{~cm}$ for a mass of $620 \mathrm{~g}$. It is perforated axially, with an iron axis attached to a ring inserted in the perforation, to allow the suspension of the weight (Figure 3). The scales have two hooks to which are attached the object to be weighed and the counterweight along the graduated arm of the scales. The balance is struck by moving a small weighted cursor along the graduated arm.
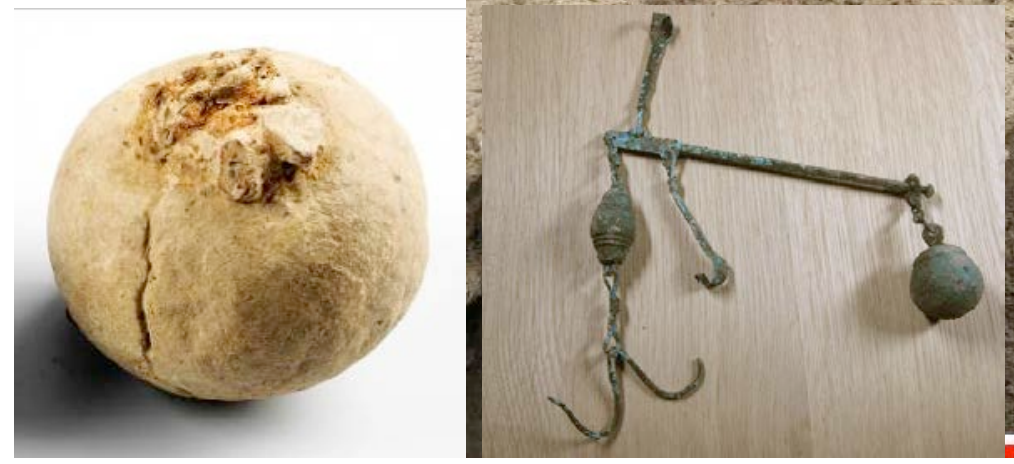

Figure 3. Weight and steelyard. (C) H. Paitier, Inrap

\section{Presentation of the Approach}

The workflow followed in our study is composed of three parts, as presented in Figure 4: 
1. Data acquisition: The initial archaeological material is digitized to produce digital data that can be manipulated without damage. Depending on the context of the study, we can use different technologies for digitization, such as photogrammetry for external digitization, or CT scan for nested objects.

2. Data processing: Data produced during the digitization step is processed to focus on specific parts of interest, and to obtain an acceptable format for 3D printing.

3. Data 3D printing: Digital objects obtained from the processing step are printed, either directly, or with a scale factor. 3D copies provide an access to the artifacts and activities. In particular, 3D objects can be used as interfaces for a reconstitution of the context in virtual reality. 


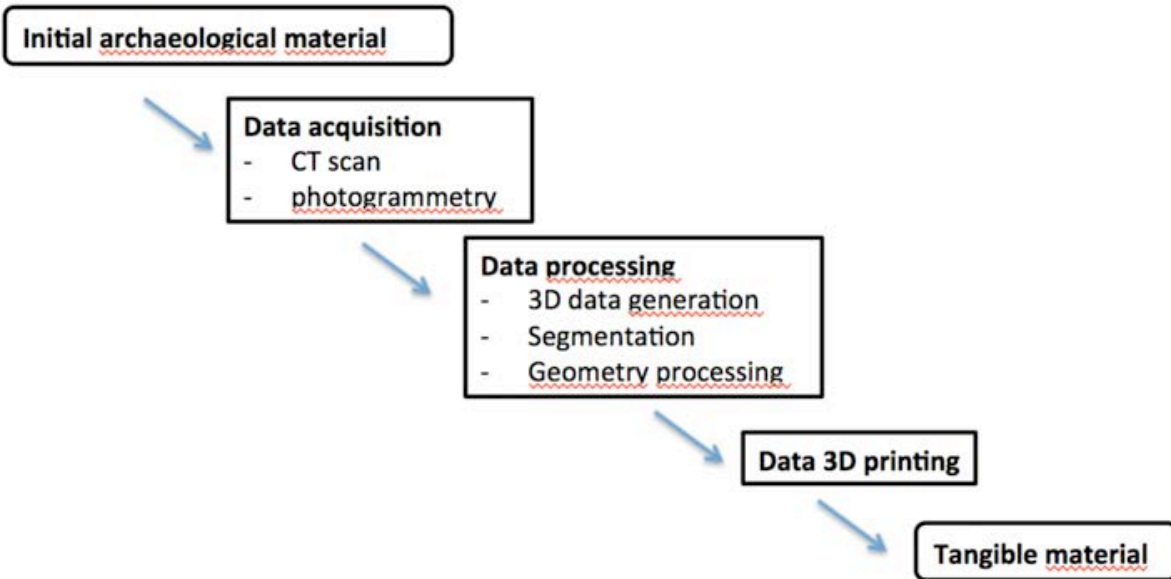

Figure 4. Presentation of the different steps of the workflow.

4. Use Cases in Practice

We will now present the different case studies performed during our work.

\subsection{The funerary urn of Saint-Pair-sur-Mer}

Our first case study is a Bronze Age funerary urn. The threedimensional explorations were performed with a CT scanner through two passes, a topogram (or radio mode) for positioning the slices to be realized and a helix scan. We used a Siemens SOMATOM Sensation 16 (Figure 5) for CT scan with technical constants set as $140 \mathrm{kV} / 600$ mAs / $240 \mathrm{~mA}$, collimation of $16 \times 0.75 \mathrm{~mm}$, slice of 0.75 every 0.3 
$\mathrm{mm}$, FoV of $450 \mathrm{~mm}$, resolution of $878.90 \mu \mathrm{m}$, on a $512 \times 512$ pixel matrix.
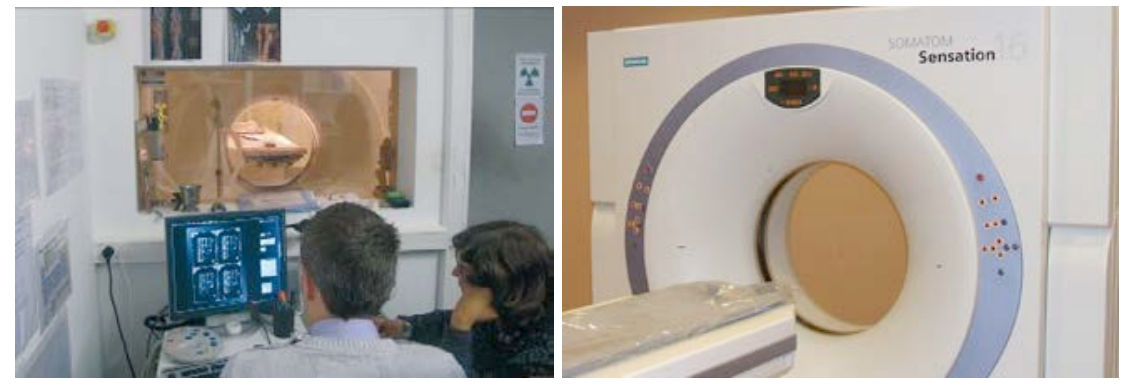

Figure 5. The CT scanner in Image ET.

Tomodensitometry analysis (slice views of the object, tomo, and density information, densito, obtained from CT san) of the urn revealed three aligned connected vertebrae (Figure 6, left). The highlight of the different components of the material is based on density information calculated during the CT scan, called the radiodensity, and expressed relatively to the Hounsfield scale (Molteni, 2011). In this scale, the zero Hounsfield unit (HU) corresponds to distilled water at standard pressure and temperature, and $-1000 \mathrm{HU}$ corresponds to air.

The weak density observed at the emplacement of the vertebrae (negative value in the Housfield scale) indicated a disaggregation of the organic matter of the bones. Standard Hounsfield density for bones is 
greater than 500, and up to $3000 \mathrm{HU}$ for dense bones. The scan generates a dataset under the standard DICOM format (Mustra et al., 2008). A segmentation of the data of DICOM images in the software OsiriX ${ }^{1}$, focusing on the low densities, enabled generation of the volume image of the vertebrae presented in Figure 6, right.

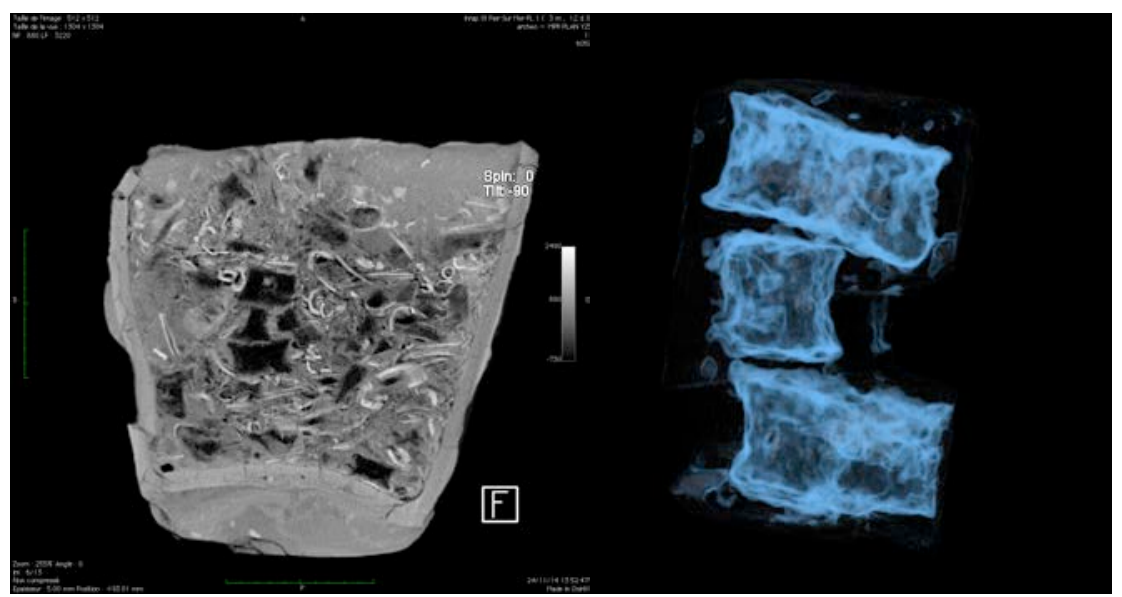

Figure 6. Left: tomography view of the urn, with the three aligned vertebrae in black, in the center. Right: volume rendering of the vertebrae.

The 3D surface renderer of OsiriX was used to produce the mesh intended for $3 \mathrm{D}$ printing. The mesh is constructed as the surface of the point cloud corresponding to an interval of radiodensity values. For the vertebrae part, the HU values considered are in the interval $[-900 ; 0]$.

\footnotetext{
${ }^{1} \mathrm{http}: / /$ www.osirix-viewer.com/
} 
The mesh obtained with this process (Figure 7) contained some noise and unwanted data: in particular, two insect galleries connected to the imprint of the vertebrae, which were removed in MeshLab (Figure 7, left). This cleaning step was performed in coordination with the archaeologist and the CT expert to control the removed parts. We also applied a smooth transformation of the mesh and filled holes due to OsiriX meshing, using Blender, to recreate a surface close to the boneshape and 3D-printable.

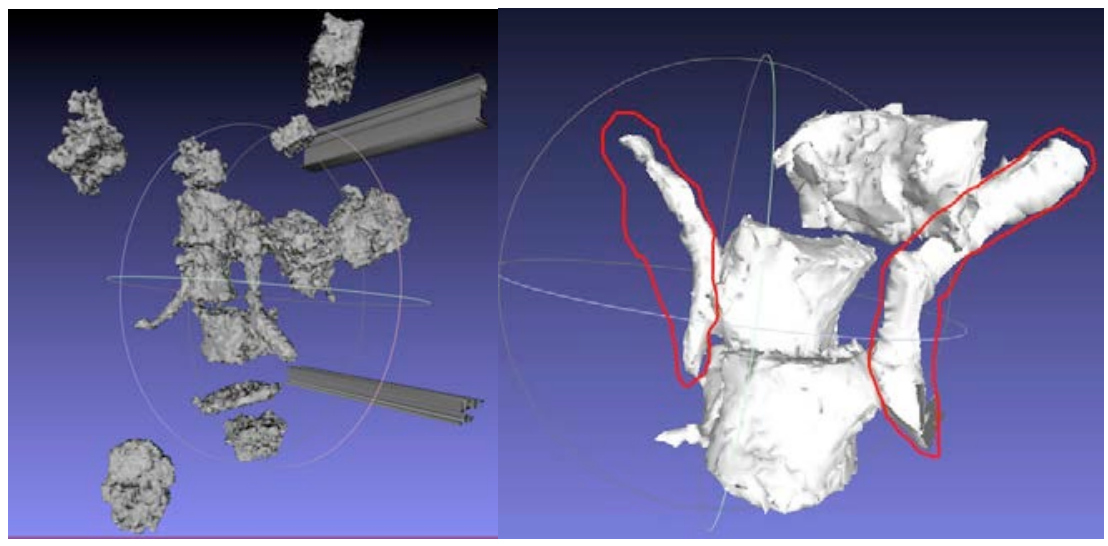

Figure 7. Left: mesh generated with OsiriX. Right: insect galleries around the vertebrae.

The upper vertebra in the mesh was disconnected from the two lower ones. We added a cylinder in the 3D modeling tool Blender (Figure 8, 
center) to obtain a single-piece object that respects the relative position of the vertebrae in the urn for 3D printing (Figure 8 , right). 3D printing was performed with a 3D printer: MakerBot Replicator 2x.

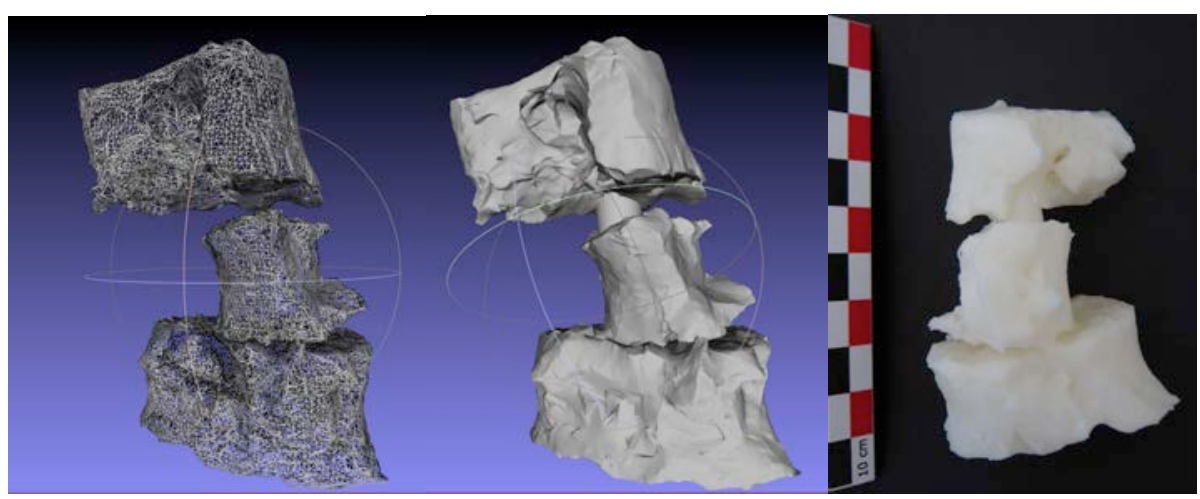

Figure 8. Left: mesh of vertebrae. Center: mesh ready to print with an intermediary cylinder to interlock the vertebrae. Right: 3D printed vertebrae.

\subsection{The Centaur of Chateaugiron}

Representatives of the municipality where the centaur was excavated asked for a large-scale copy of the sculpture for public exhibition. Such copies are usually made by artists and are quite expensive. We wanted to explore a replication process that would be cheaper, and could be easily repeated to make more than one copy. 
As we were interested in very precise details of the external shape of the centaur statue, to be able to provide an enlargement, we explored different acquisition approaches.

We first experimented with a CT scan of the statue with technical constants set as $140 \mathrm{kV} / 700 \mathrm{mAs} / 233 \mathrm{~mA}$, collimation of $16 \times 0.75 \mathrm{~mm}$, slice of 0.75 every $0.1 \mathrm{~mm}, \mathrm{FoV}$ of $80 \mathrm{~mm}$, resolution of $156.25 \mu \mathrm{m}$, on a $512 \times 512$ pixel matrix. But the bronze was too dense for the X-ray power of the scanner, resulting in the production of noise and blind cones, as presented in Figure 9. On the left image, on a slice at the head and right arm level, the blind cone and X-ray diffractions are visible. On the two right images, the $3 \mathrm{D}$ reconstruction of the centaur from the CT scan is not exploitable.

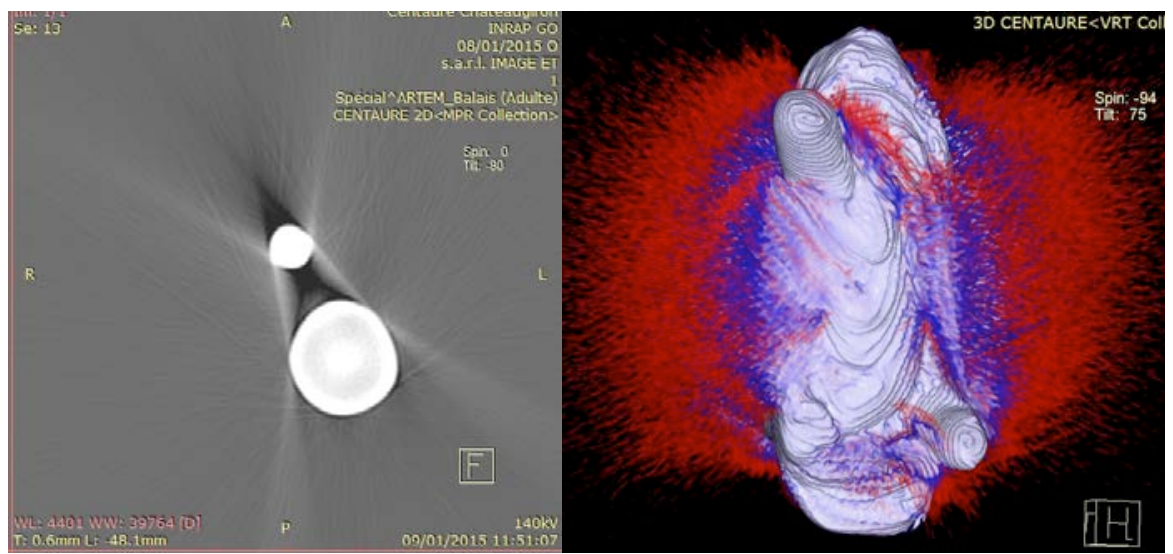

Figure 9. CT scan of the centaur. 
We thus decided to digitize the statue with photogrammetry scan (Figure 10).

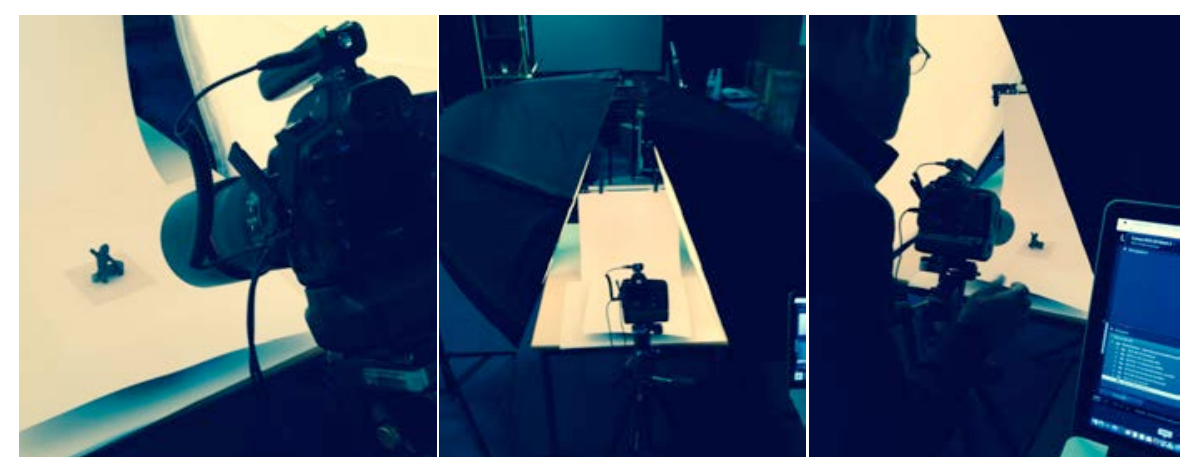

Figure 10. Photogrammetry capture of the centaur.

We used a DSLR Canon 5DmkII, a 21.1-megapixel full-frame CMOS digital single-lens reflex camera, with a lens type Canon EF 100 $\mathrm{mm}$ f/2.8 Macro USM. The studio was equipped with 2 flashes, Walimex PRO VC-300 with Softbox, to have a uniform lightening with minimal shadows. The object was presented on a graph paper, with a white background, and placed on a turntable.

The capture was performed in two passes, first with the object standing up, and second with the object lying on its side, to have a complete cover of the object. The second series aimed at providing the bottom part of the centaur. For each pass, the camera was oriented at $45^{\circ}$ with 
respect to the horizontal. For the first pass, we took 66 photos, and for the second pass, 81 photos. The raw pictures were transformed into jpeg, with a resolution of $5616 \times 3744 \mathrm{px}$, using the software, Lightroom 5.7, with increase of contrast, clarity, and sharpness. We used Agisoft PhotoScan standard edition to align the photos (Figure, 11 left) and generate a point cloud. For the first series, we obtained 2690 tie points for alignment and a dense cloud of 33.5 million points (ultra-high quality, Figure 11, right). For the second series, we obtained 7980 tie points and a dense cloud of 9.5 million points (high quality).
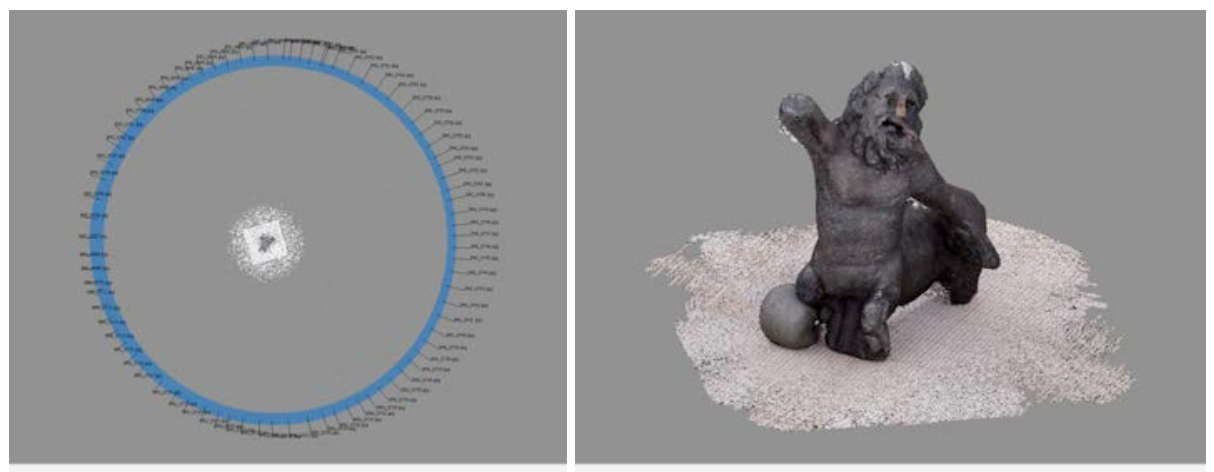

Figure 11. Left: alignment of the photos. Right: dense point cloud.

We used MeshLab and CloudCompare software to manually remove the useless parts of point clouds (graph paper, and upper part of the centaur in the second series), and we obtained a clean point cloud of 
approximately 20 million points for the first series and approximately 360 thousand points for the second series.

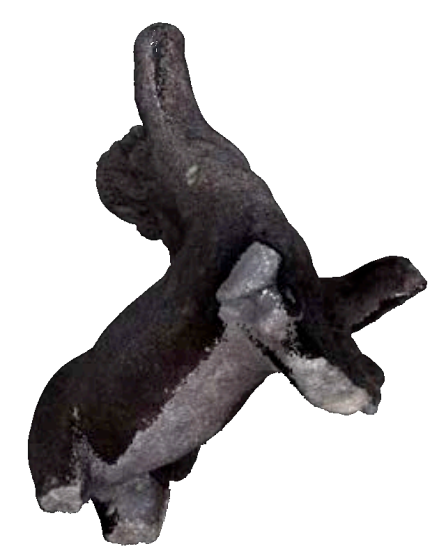

Figure 12. Fusion of top and bottom point clouds.

The two point clouds were aligned with CloudCompare using selections of equivalent points in each cloud (point pairs picking) for an initial registration, then ICP algorithm for a finer alignment. The resulting point cloud had a size of approximately 20 million points (Figure 12).

The mesh was generated with CloudCompare via screened Poisson reconstruction (depth 11), and the faces were colored. The resulting mesh contained 9.5 million points and 19 million faces. 
We reduced the number of faces to one million with the Quadric Edge Collapse Decimation filter in MeshLab (Figure 13). The details of the face of the centaur, on the right part of Figure 13, illustrate the accuracy of the mesh, even after optimization. We finally generated an STL file to be handled by our 3D printer.
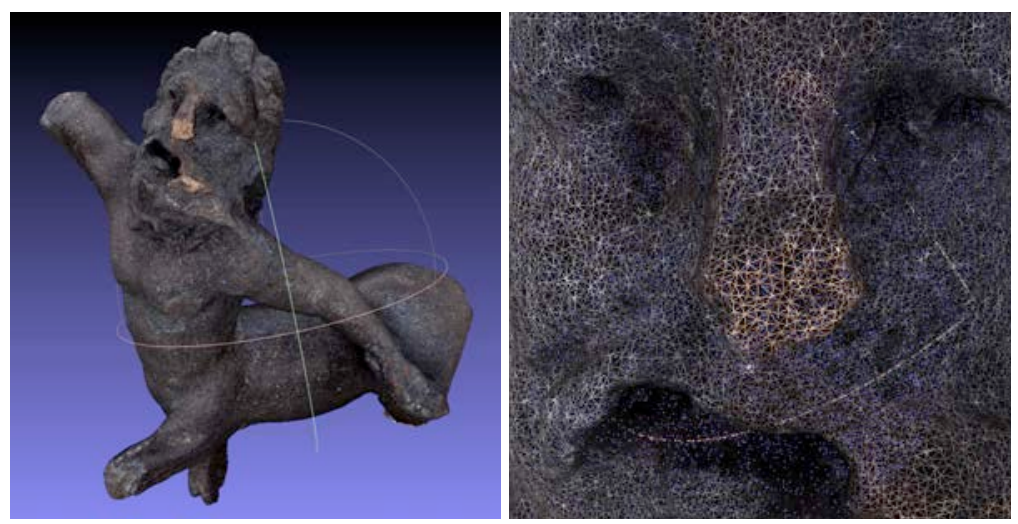

Figure 13. Left: 1M faces mesh. Right: detail of the face of the centaur in the $1 \mathrm{M}$ polygon mesh.

Two versions of the centaur were printed, one at 1:1 scale, and one at $\times 2.8$ scale (Figure 14). 


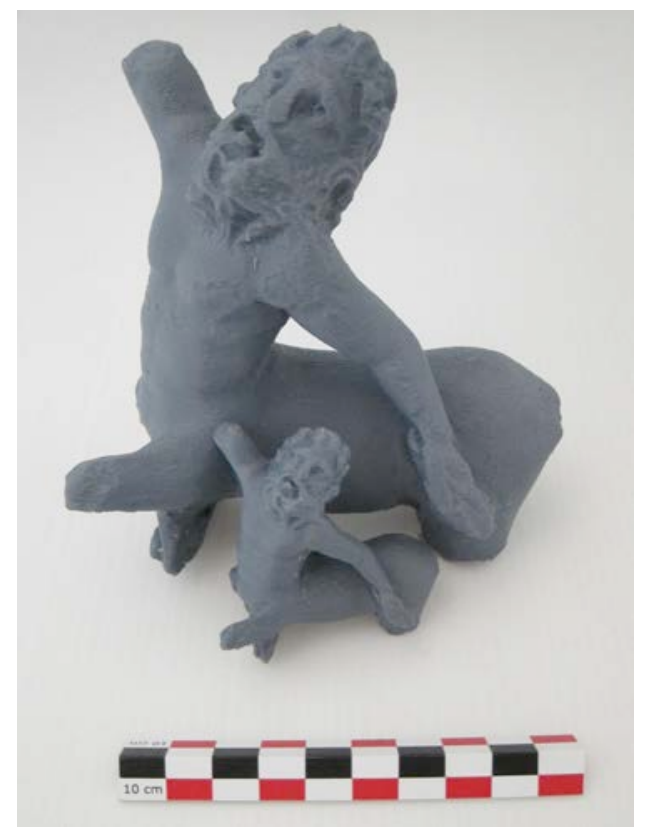

Figure 14. 3D printed versions of the centaur.

\subsection{Weighing activity}

The scales are based on a model obtained from a CT scan performed in a previous study. The model of the steelyard was made by a graphic designer using the Parville balance (Figure 15). 


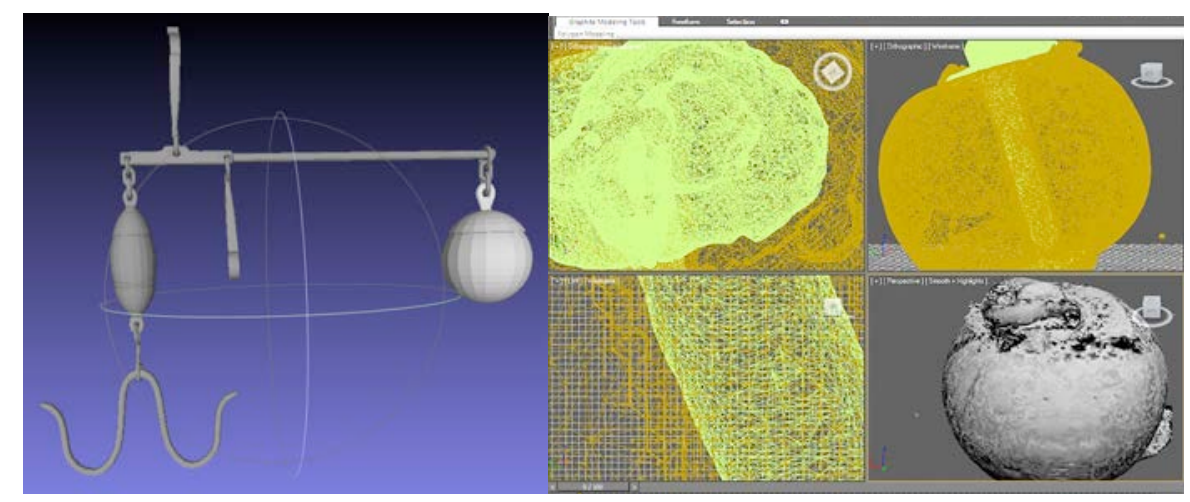

Figure 15. Models for the steelyard and the granite weight.

The two models were integrated in a VR immersive reconstitution of the Gallo-Roman villa Bourg-Saint-Pere (Gaugne et al., 2013) under Unity 3D. The steelyard is hooked to a metal bar between two wooden pillars, in front of the estate manager's house (Figure 16). Three jute bags of different sizes are placed on a table, next to the weighing machine. 


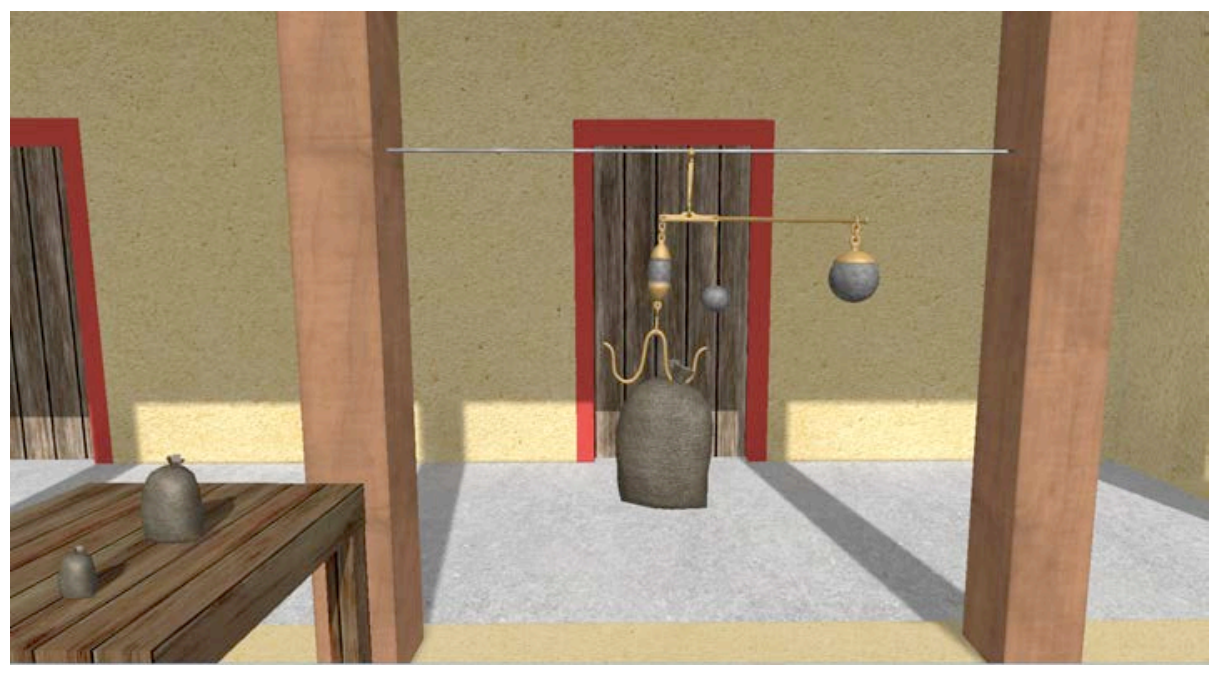

Figure 16. The steelyard in its VR context.

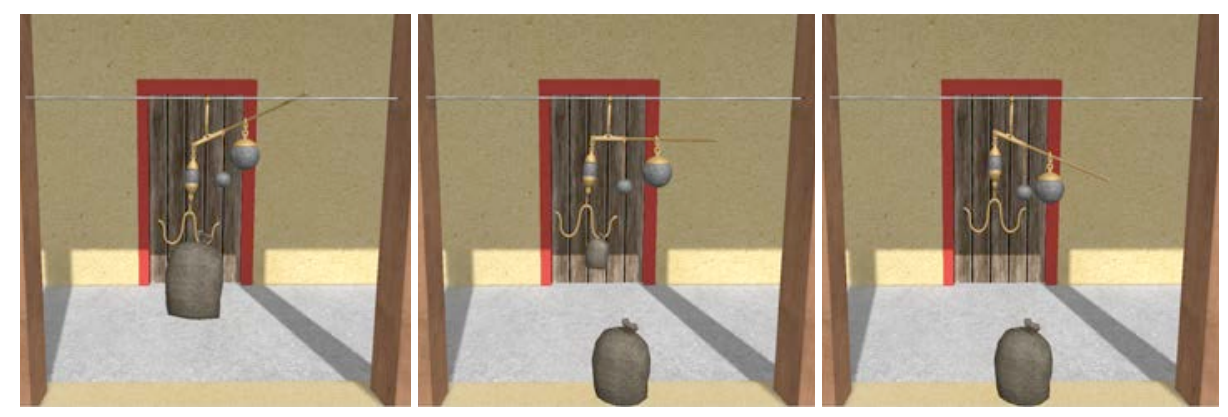

Figure 17. Physical behavior of the system.

We used the Unity 3D physical engine to implement a coherent behavior of the system (Figure 17). The user can interact through the 3D-printed copy of the weight (Figure 18) and its hand with tracking target. 

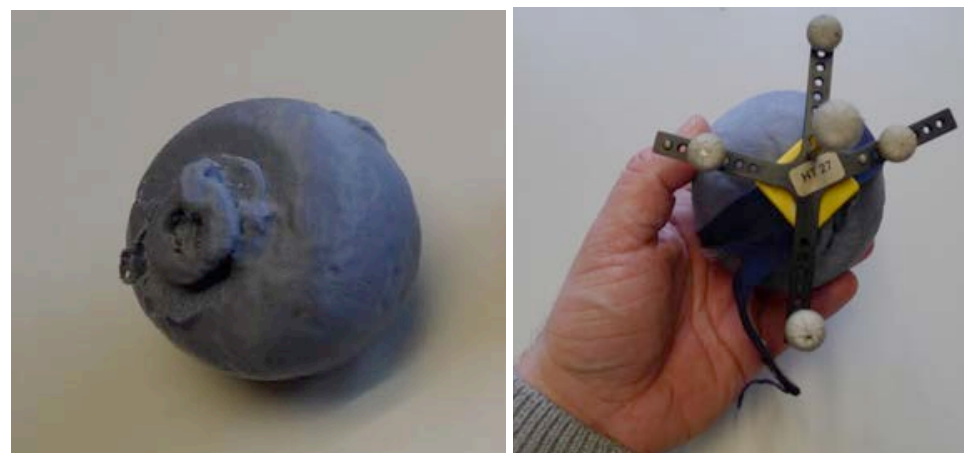

Figure 18. 3D printed weight as tangible interface, with tracking target.

The weight is used to interact with the virtual weight in the steelyard, and attach or detach it during the weighing activity (Figure 19).

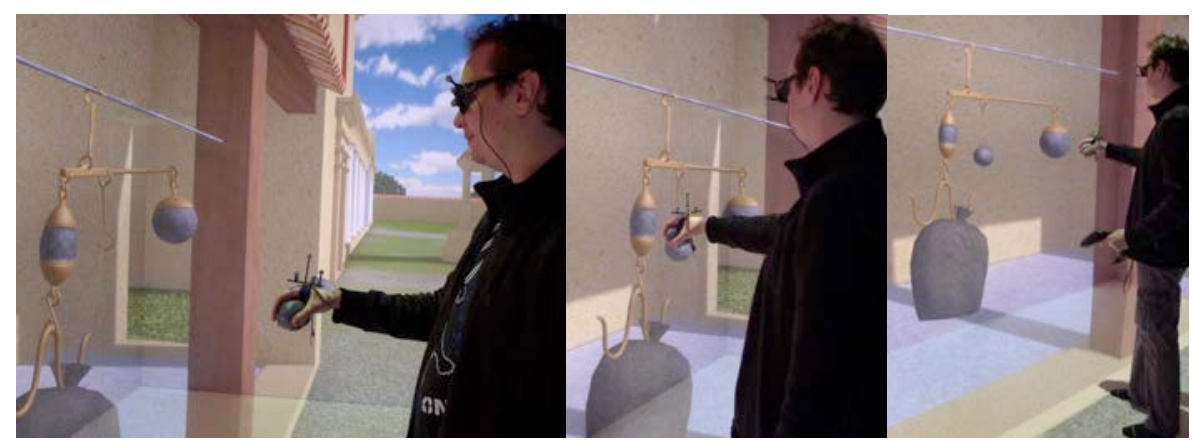

Figure 19. Tangible positioning of the weight on the weak part.

The user can catch the different bags with the tracked hand, hang them to the hook of the steelyard, and move the counterbalance along the arm to adjust the balance (Figure 20). 


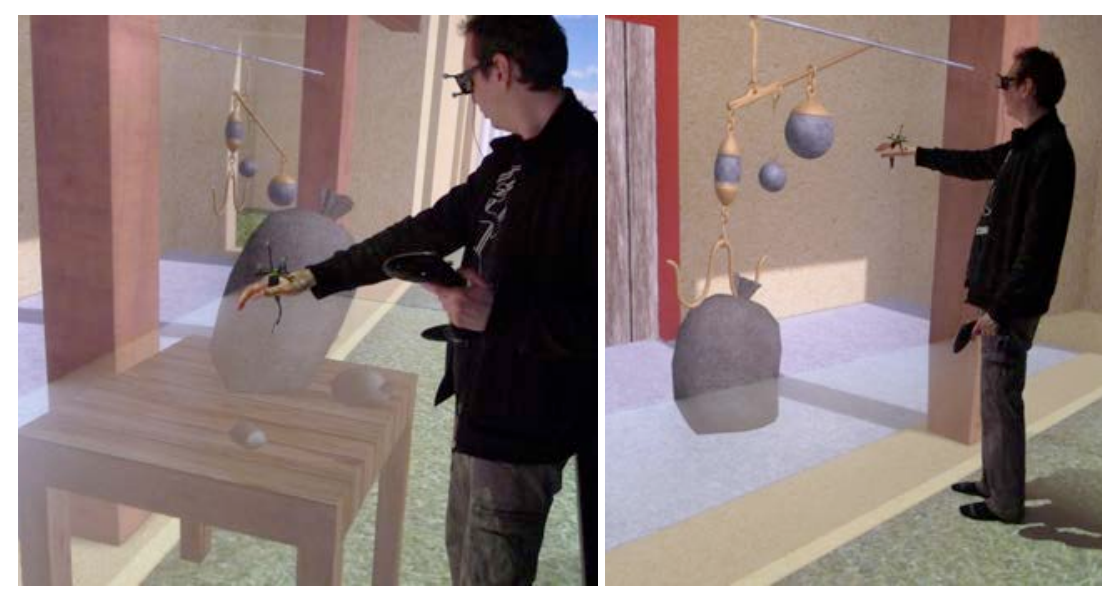

Figure 20. Interactions for weighing activity.

\section{Discussion}

The usefulness of 3D printing technologies for cultural heritage is currently largely admitted, mainly for museum exhibition and restoration purposes. In both cases, the goal is to rebuild artifacts as faithful as possible to obtain a concrete $3 \mathrm{D}$ representation, which can be safely manipulated.

However, 3D printed objects can, in fact, represent more than a simple copy of actual reality. In our approach, the intermediate steps of advanced digitization and digital model processing can provide access 
to representation of unreachable (vertebrae) or non-existent (scaled sculpture) objects.

The case study of the funerary urn of Saint-Pair-sur-Mer illustrates two simultaneous, frequent situations faced by archaeologists: (i) blind analysis of archaeological material where one must decide to physically destroy the original material without knowledge of the content and with the risk of losing information, and (ii) analysis of vanished material from imprints and partial presence clues. Analysis of the funerary urn with tomography highlights elements that are invisible to the eye, because they are encased in a block of ashes, and they are heavily damaged because organic matter was decomposed with time. It also allows access to some parts without having to break the urn and risk destroying its fragile content. Tomography allows spatial localization of all artifacts and their identification. This information allows us to anticipate optimally fine analysis of clusters and to implement protective measures for artifacts. Three-dimensional acquisition associated with 3D printing offers the possibility to duplicate an artifact (among other advantages), leading to an immediate typological identification of the artifact. This is in addition to morphological, typometric, or technological observations, and regardless of contingencies 
relative to conservation and restoration operations often required by such objects. Three-dimensional visualization facilitates observations of empty spaces and wall effects, and thus allows characterization of funeral gestures (presence of perishable container or offerings). It is also possible to generate images that will be used to support speech. The 3D printing of the vertebrae allows the manipulation of these elements and their analysis by anthropology specialists. After our study, an excavation of the content of the urn confirmed that the matter of the vertebrae was completely disaggregated. They could not have been identified and studied simply by performing a physical excavation of the urn. In this case, the imagery and 3D printing become a permanent virtual record of the object's original state, thus allowing ulterior observations and study.

In the case of the Centaur of Chateaugiron, the original object still exists, but its size and rarity prevent it from being easily manipulated, shared, and exhibited. This is the case for many small artifacts studied by archaeologists. The acquisition of a 3D model of this item associated to $3 \mathrm{D}$ printing appears to be a quick and inexpensive alternative to study and share this type of object. The same process can be applied to smaller artifacts such as jewels and ornaments, with 
interesting possibilities of scaling, complex artifacts (assemblages, locking mechanisms, padlocks), or fragile (textile, perishable furniture). The case of the weighing activity with the steelyard and weight constitutes another promising use of 3D printing. The last step of our process allows us to contextualize tangible representations of artifacts using virtual reality. In this case, the $3 \mathrm{D}$ printed object becomes a tangible interface to recreate a human activity. The association of physical representation of an object and its context of use increase the understanding of past activities. Handling an artifact or its copy, and trying to imagine how it was used, is generally not sufficient to apprehend the physical reality of the gesture associated to the manipulation of the object in its context. The simulation of the steelyard, with a realistic physical behavior, allows study of the different steps of weighing. Alternatively, a study of the weighing performed strictly virtually could also be possible, but it entails a weaker implication of the user in the interaction, and thus a less accurate understanding of the activity. For example, this is particularly important if we want to reconstitute a realistic human activity for motion capture. In this case, the actor playing the activity needs tangible accessories to accompany his or her gestures. 
Overall, the three case studies, which are presented here, gather different technologies in a process that constitutes a toolbox with several fundamental advantages for archaeologists and cultural heritage practitioners:

- These technologies are preservative. This is a key concern in daily work of archaeologists, as destructive analysis always causes the loss of information. Preserving the original material can give access to subsequent analyses, with the emergence of further improved technologies.

- They improve efficiency, helping archaeologist to evaluate the interest of archaeological material. The archaeologist has access to immediate information on invisible data, drastically improving the diagnostic.

- They are time and cost saving. The scan of a funerary urn takes a few minutes, while physical excavation of the same urn takes about a week.

From a computer science viewpoint, these case studies developed in close collaboration with archaeologists question the validity and relevancy of the representation of archaeological artifacts. As we targeted the improvement of the archaeological process, we had to be 
particularly careful of the relationship between the archaeologist and the data. It appeared that archaeologists were not always comfortable with 3D digital data, but they were very receptive to two types of data:

- Hidden data revealed by CT scan. The immediate access to a rich representation of invisible and inaccessible information appeared to be an obvious improvement for the work of the archaeologists involved in this study and inspired them to use CT scan in other contexts of their work.

- Concrete 3D data. Archaeologists have a particular relationship to physical objects during their studies, with an important emphasis on touching and manipulating the objects. Three-dimensional printed objects provided in this work nourished many exchanges between experts in different domains of archaeology, constituting a concrete shared representation of data and embedding valuable information on how objects were produced and used in the past.

Nevertheless, further work is required to adapt these technologies for the specificities of archaeological and cultural heritage. In particular, the software related to DICOM image processing is very well suited for medical applications but would require some adaptations for 
archaeological objects (focus on the volume and surface 3D rendering, better handling of extended Hounsfield scale that is more adapted to dense material such as metal). It would also be interesting to directly integrate $3 \mathrm{D}$ printing features in the DICOM management process to obtain a more uniform toolbox.

\section{Conclusion and Future Works}

We combined tomography, digitization, 3D printing, and virtual reality to create the concrete representations and usages of artifacts that are not accessible. We obtained (i) an object that is no longer preserved (the vertebra), (ii) an object that has never existed (the centaur with scale $\times 2.8$ ), (iii) an action within a context that no longer exists (Iron Age weighing). We previously used the same process to obtain a tangible access to objects encased in another mass (the weight axis), in a block of ashes (fibula), and a mass of rust (helical element).

These different use cases illustrate the interest of combining digital images, 3D printing, and virtual reality for cultural heritage. This combination constitutes a comprehensive workflow from archaeological material to tangible representations of artifacts and their 
usage. Such tangible objects can be used for study, preservation, or presentation.

We plan to pursue this work by enriching the different steps. As an example, we are currently investigating different technologies of 3D printing with use of other materials, such as metal or resin with finish coat, to produce copies closer to original artifacts. We are also considering other artifacts (tools, and marine instruments) to be used in virtual reality, within motion capture sessions. Artifact copies produced by 3D printing are good candidates for mixed-reality technologies, especially in augmented-reality situations in which the 3D object can be used as support to display additional information (textures, missing parts, etc.)

\section{References}

Arbace, L., Sonnino, E.,Callieri, M.,Dellepiane, M., Fabbri, M.,Idelson, A. I., and Scopigno, R. (2013). Innovative uses of 3D digital technologies to assist the restoration of a fragmented terracotta statue, Journal of Cultural Heritage Volume 14, Issue 4, pp. 332-345.

Arnold, D. (2014). Computer Graphics and Cultural Heritage, Part 2: Continuing Inspiration for Future Tools. In IEEE Computer Graphics and Applications, vol. 34, no. 4, pp. 70-79. 
Bale, K., D., Abbott, Gowigati, Pritchard, D., Chapman, P. (2011) Linking Evidence with Heritage Visualization using a large Scale Collaborative Interface, in proc. of VAST 2011 Int. Symp. on Virtual Reality, Archaeology and Intelligent Cultural Heritage, pp 121-128.

Balleri, R., Di Tondo, S., Adembri, G., Gherardelli, M. (2014). 3D Laser Scanning of Historic Molds for Documenting the Richard-Ginori Factory Collection. Journal of the American Institute for Conservation 53:3, 145-158.

Barreau, J-B., Nicolas, T., Bruniaux, G., Petit, E., Petit, Q., Bernard, Y., Gaugne, R. and Gouranton, V. (2015). Photogrammetry Based Study of Ceramics Fragments, in International Journal of Heritage in the Digital Era, Vol. 3, No. 4, DOI 10.1260/20474970.3.4.643

Christou, C., Angus, C., Loscos, C., Dettori, A., Roussou, M. (2006). A versatile large-scale multimodal VR system for cultural heritage visualization, in proc. Of VRST06 Symp. on Virtual reality software and technology, ACM, pp 133-14.

Gallo, G., Muzzupappa, A., Bruno, F. (2013). 3D reconstruction of small sized objects from a sequence of multi-focused images. In Journal of Cultural Heritage, Vol. 15(2), pp. 173-182 Gaugne R., Le Cloirec G., Barreau J.-B., Gouranton V. (2013). Experiencing the past in virtual reality A virtual reality event for the French National Days of Archaeology. In 4th IEEE International Conference on Cognitive Infocommunications, Budapest, Hongrie, dec. 2013, pp. 1-6.

Harvig, L. L., Lynnerup, N., \& Amsgaard Ebsen, J. (2012). Computed Tomography and Computed Radiography of late Bronze Age Cremation Urns from Denmark: An interdisciplinary attempt to develop methods applied in Bioarchaeological cremation research. Archaeometry, 54(2), 369-387. 10.1111/j.1475-4754.2011.00629.x

Hassmann, H., Heintgeis, T., Rasink, B., Winghart, S., Wulf, F.-W. (2012). Der bronzezeitliche Hortfund von Gessel, Stadt Syke, Landkreis Diepholz, Denkmalplege. In Berichte zur Niedersachsen, ISSN 0720-9835Jg 32, Nr. 1, pp23-28. 
Haugstvedt AC, Krogstie J. (2012). Mobile augmented reality for cultural heritage: A technology acceptance study, in Proceedings of IEEE International Symposium on Mixed and Augmented Reality (ISMAR), pp. 247-255.

Herman, G. T. (2009). Fundamentals of computerized tomography: Image reconstruction from projection, 2nd edition, Springer

Hess, M., \& Robson, S. (2013). Re-engineering Watt: A case study and best practice recommendations for $3 \mathrm{D}$ colour laser scans and $3 \mathrm{D}$ printing in museum artefact documentation. Lasers in the Conservation of Artworks IX, 154-162. London, UK: Archetype.

Hughes, S. (2011). CT Scanning in Archaeology, in Computed Tomography - Special Applications, L. Saba Ed., InTech,

Lapp, E., Nicoli, J. (2014) Exploring 3D modeling, fingerprint extraction, and other scanning applications for ancient clay oil lamps, in Digital Applications in Archaeology and Cultural Heritage, Volume 1, Issue 2, Pages 34-44.

Laycock, S., Bell, G., Mortimore, D., Greco, M., Corps, N., Finkle, I. (2012). Combining XRay Micro-CT Technology and 3D Printing for the Digital Preservation and Study of a 19th Century Cantonese Chess Piece with Intricate Internal Structure, in ACM Journal on Computing and Cultural Heritage, Vol. 5, No. 4

Liestøl, G. (2014). Along the Appian Way. Storytelling and Memory across Time and Space in Mobile Augmented Reality, In Marinos Ioannides (ed.), Progress in Cultural Heritage. Documentation, Preservation and Protection. Springer. ISBN 978-3-319-13695-0. 24. s $248-257$

Magnenat-Thalmann, N, Papagiannakis, G. (2005). Virtual worlds and augmented reality, in Cultural Heritage applications, Recording, modeling and visualization of cultural heritage, $419-430$ 
McKnight, L. M., Adams, J. E., Chamberlain, A., Atherton-Woolham, S. D., Bibb, R. (2015). Application of clinical imaging and 3D printing to the identification of anomalies in an ancient Egyptian animal mummy, in Journal of Archaeological Science: Reports, Volume 3, Pages 328-332, ISSN 2352-409X, http://dx.doi.org/10.1016/j.jasrep.2015.06.028.

Molteni, R. (2011). From CT numbers to Hounsfield Units in cone beam volumetric Imaging: the effect off artifacts. $A A O M R$, Chicago.

Morgan, C. L. (2009). (re)building catalhoyuk : Changing virtual reality in archaeology, Archaeologies, Journal of the World Archaeological Congress 5(3):468-487.

Mustra, M., Delac, K., Grgic, M., (2008). Overview of the DICOM Standard. ELMAR. 50th International Symposium. pp. 39-44.

Nicolae, C.; Nocerino, E.; Menna, F.; Remondino, F. (2014). Photogrammetry applied to Problematic artefacts ISPRS - International Archives of the Photogrammetry, Remote Sensing and Spatial Information Sciences, Volume XL-5, pp.451-456

Nicolas, T., Gaugne, R., Tavernier, C., Gouranton, V., Arnaldi, B. (2014). Preservative approach to study encased archaeological artefacts, In Proceedings of EUROMED 2014 International Conference on Cultural Heritage, LNCS 8740, Limassol, Cyprus, Nov. 2014, pp332-341.

Re, A., Corsi, J., Demmelbauer, M., Martini, M., Mila, G. and Ricci, C., X-ray tomography of a soil block: a useful tool for the restoration of archaeological finds, Heritage Science (2015) 3:4, DOI 10.1186/s40494-015-0033-6

Scopigno, R., Cignoni, P., Pietroni, N., Dellepiane, M. (2014) Digital Fabrication Technologies for Cultural Heritage (STAR), 12th EG Symp. on Graphics and Cultural heritage, Darmstadt, Germany (in press).

Stelzner, J., Ebinger-Rist, N., Peek, C., Schillinger B. (2010). The application of 3D computed tomography with X-rays and neutrons to visualize archaeological objects in blocks of soil. In Studies in Conservation 06/2010; 55(2):95-106. DOI:10.1179/sic.2010.55.2.95 
Uda, M. and Demortier, G. and Nakai, I. and Applbaum, N. and Applbaum, Y. H. (2005). The

Use of Medical Computed Tomography (CT) Imaging in the Study of Ceramic and Clay Archaeological Artifacts from the Ancient Near East, in X-rays for Archaeology, Springer Netherlands, pp 231-245

\section{Figure captions}

Figure 1. The funerary urn of St-Pair-sur-Mer. CM. Le Puil-Texier, Inrap

Figure 2. The bronze centaur. CD. Gliksman, Inrap

Figure 3. Weight and steelyard. (C) H. Paitier, Inrap

Figure 4. Presentation of the different steps of the workflow.

Figure 5. The CT scanner in Image ET.

Figure 6. Left: tomography view of the urn, with the three aligned vertebrae in black, in the center. Right: volume rendering of the vertebrae.

Figure 7. Left: mesh generated with OsiriX. Right: insect galleries around the vertebrae.

Figure 8. Left: mesh of vertebrae. Center: mesh ready to print with an intermediary cylinder to interlock the vertebrae. Right: 3D printed vertebrae.

Figure 9. CT scan of the centaur.

Figure 10. Photogrammetry capture of the centaur.

Figure 11. Left: alignment of the photos. Right: dense point cloud.

Figure 12. Fusion of top and bottom point clouds.

Figure 13. Left: $1 \mathrm{M}$ faces mesh. Right: detail of the face of the centaur in the $1 \mathrm{M}$ polygon mesh.

Figure 14. 3D printed versions of the centaur.

Figure 15. Models for the steelyard and the granite weight. 
Figure 16. The steelyard in its VR context.

Figure 17. Physical behavior of the system.

Figure 18. 3D printed weight as tangible interface, with tracking target.

Figure 19. Tangible positioning of the weight on the weak part.

Figure 20. Interactions for weighing activity. 